\title{
In-situ Infrared Characterization During Atomic Layer Deposition of Lanthanum Oxide
}

\section{Citation}

Kwon, Jinhee, Min Dai, Mathew D. Halls, Erik Langereis, Yves J. Chabal, and Roy G. Gordon. 2009. In-situ infrared characterization during atomic layer deposition of lanthanum oxide. Journal of Physical Chemistry C 113, no. 2: 654-660.

\section{Published Version}

http://dx.doi.org/10.1021/jp806027m

\section{Permanent link}

http://nrs.harvard.edu/urn-3:HUL.InstRepos:3347570

\section{Terms of Use}

This article was downloaded from Harvard University's DASH repository, and is made available under the terms and conditions applicable to Other Posted Material, as set forth at http:// nrs.harvard.edu/urn-3:HUL.InstRepos:dash.current.terms-of-use\#LAA

\section{Share Your Story}

The Harvard community has made this article openly available.

Please share how this access benefits you. Submit a story.

Accessibility 


\title{
In Situ Infrared Characterization during Atomic Layer Deposition of Lanthanum Oxide
}

\author{
Jinhee Kwon, ${ }^{* \dagger}{ }^{\dagger}$ Min Dai, ${ }^{\ddagger}$ Mathew D. Halls, ${ }^{\S}$ Erik Langereis, ${ }^{\prime}$ Yves J. Chabal, ${ }^{\dagger}$ and \\ Roy G. Gordon ${ }^{\perp}$ \\ Department of Materials Science and Engineering, University of Texas at Dallas, Richardson, Texas 75080, \\ Laboratory for Surface Modification, Rutgers University, Piscataway, New Jersey 08854, Materials Science \\ Division, Accelrys Inc., San Diego, California 92121, Applied Physics, Plasma and Materials Processing, \\ Eindhoven University of Technology, Eindhoven, The Netherlands, Department of Chemistry and Chemical \\ Biology, Harvard University, Cambridge, Massachusetts 02138
}

Received: July 8, 2008; Revised Manuscript Received: November 5, 2008

\begin{abstract}
Mechanisms of atomic layer deposition (ALD) growth of lanthanum oxide on H-terminated $\mathrm{Si}(111)$ using lanthanum tris $\left(N, N^{\prime}\right.$-diisopropylacetamidinate) $\left(\mathrm{La}\left({ }^{i} \mathrm{Pr}-\mathrm{MeAMD}\right)_{3}\right)$ are investigated using infrared (IR) absorption spectroscopy. The reactivity of this amidinate precursor is high, with almost all surface $\mathrm{Si}-\mathrm{H}$ bonds consumed after 5 ALD cycles at $300^{\circ} \mathrm{C}$. Gas phase IR spectra show that, although most of the precursor $\left(\mathrm{La}\left({ }^{i} \mathrm{Pr}-\mathrm{MeAMD}\right)_{3}\right)$ remains intact, a strong feature at $1665 \mathrm{~cm}^{-1}$, characteristic of a hydrogenated and dissociated free ligand with localized electrons in the $\mathrm{N}-\mathrm{C}=\mathrm{N}$ bonds, is present. Such partial precursor dissociation in the gas phase is due to hydrolysis by traces of water vapor remaining in the reactor, even after purging. As a result, some $\mathrm{Si}-\mathrm{O}-\mathrm{La}$ bonds are formed upon reaction with the surface during the first $\mathrm{La}\left({ }^{i} \mathrm{Pr}-\right.$ $\mathrm{MeAMD})_{3}$ pulse, prior to any water pulse. During film growth, acetate/carbonate and hydroxyl impurities are incorporated into the film. Annealing to $500{ }^{\circ} \mathrm{C}$ in dry $\mathrm{N}_{2}$ removes these impurities but fosters the growth of interfacial $\mathrm{SiO}_{2}$. Deposition at $300{ }^{\circ} \mathrm{C}$ leads to decomposition of adsorbed ligands, as evidenced by the formation of cyanamide or carbodiimide vibrational bands (or both) at 1990 and $2110 \mathrm{~cm}^{-1}$, respectively. Despite this decomposition, ideal self-limited ALD growth is maintained because the decomposed ligands are removed by the subsequent water pulse. Growth of pure lanthanum oxide films is often characterized by nonuniform film thickness if purging is not complete because of reversible absorption of water by the $\mathrm{La}_{2} \mathrm{O}_{3}$ film. Uniform ALD growth can be maintained without a rigorous dry purge by introducing alternating trimethylaluminum (TMA)/ $\mathrm{D}_{2} \mathrm{O}$ ALD cycles between $\mathrm{La} / \mathrm{D}_{2} \mathrm{O}$ cycles.
\end{abstract}

\section{Introduction}

Atomic layer deposition (ALD) of a variety of thin film materials is being thoroughly investigated because of the thickness and composition control and uniformity that it provides, even on structured substrates. ${ }^{1}$ ALD is a modified chemical vapor deposition (CVD) process in which each precursor is introduced into a reactor alternatively separated by a purging/pumping process. When compared to CVD, the selfsaturation for each precursor leads to a good interface quality and better step coverage of high-aspect ratio features. ALD is also a lower temperature process than CVD. The precursor chemistry at the surface is critical for successful ALD growth. Indeed, the small number of suitable ALD precursors limits wider applications of the technique. To make ALD growth possible, precursors must satisfy many stringent criteria, such as thermal stability, high volatility, and efficient self-limited reactivity with surfaces. The reactions on the surface and during growth must be as complete as possible to minimize incorporation of impurities in the films.

Recently, amidinate $\left(\left[\mathrm{R}^{1} \mathrm{NC}\left(\mathrm{R}^{2}\right) \mathrm{NR}^{3}\right]^{-}\right)$ligands have been incorporated into transition metal and lanthanide catalysts. ${ }^{2-5}$ These catalysts are used in solution, so the volatility of these

\footnotetext{
* Corresponding author. E-mail: jinhee@utdallas.edu.

$\uparrow$ University of Texas at Dallas.

* Rutgers University.

$\S$ Accelrys Inc.

"Eindhoven University of Technology.

${ }^{\perp}$ Harvard University.
}

amidinate compounds was never tested. In fact, these catalytic amidinate compounds have usually been made with large, heavy substituents that preclude any volatility. In addition, many catalysts are used as ionic complexes that are not volatile. Thus amidinate compounds had not been considered as possible precursors for ALD until recently, when a number of volatile metal amidinates were synthesized ${ }^{6}$ and their suitability for ALD was demonstrated. ${ }^{7}$ Metal amidinates have a number of advantages as ALD precursors. Because they have no $\mathrm{M}-\mathrm{C}$ bonds, carbon incorporation into the films may be suppressed, and the relatively reactive $\mathrm{M}-\mathrm{N}$ bonds make low-temperature deposition possible. Their steric and electronic properties can be easily tailored through variations of $\mathrm{C}$ - and $\mathrm{N}$-substituents. ${ }^{8}$ Amidinate ligands are also known to enhance the thermodynamic stability of their complexes due to the chelating effect of the bidentate ligands. ${ }^{910}$ Some transition metals, such as $\mathrm{Cu}, \mathrm{Co}, \mathrm{Fe}, \mathrm{Ru}, \mathrm{Mn}$, and $\mathrm{Ni}$, as well as their nitrides and oxides and rare earth oxides have been successfully grown by ALD from the corresponding amidinate precursors. ${ }^{7,11-16}$ However, the surface chemistry of these relatively new precursors has not yet been investigated in situ, because most studies to-date have focused on ex situ film characterization by electrical, physical, or chemical measurements.

The present work focuses on initial surface nucleation mechanisms, amidinate ligand elimination, precursor decomposition and contamination incorporation, and interface evolution during ALD using in situ Fourier transform infrared spectroscopy (FTIR). For this study, we use lanthanum tris $\left(N, N^{\prime}-\right.$ diisopropylacetamidinate) $\left(\mathrm{La}\left({ }^{i} \mathrm{Pr}-\mathrm{MeAMD}\right)_{3}\right)$ and water $\left(\mathrm{D}_{2} \mathrm{O}\right)$ 


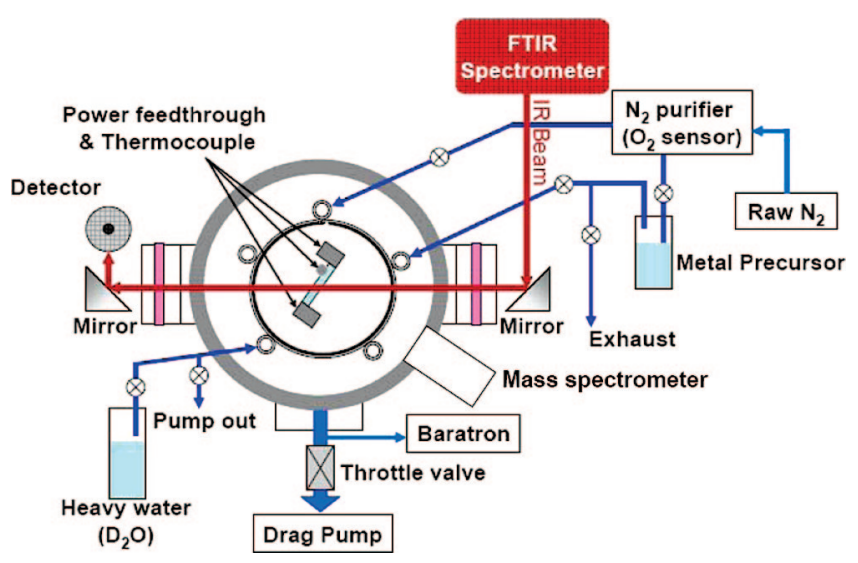

Figure 1. Schematic diagram of the ALD reactor connected to an IR spectrometer for in situ surface characterization. $\mathrm{KBr}$ windows for IR transmission are protected by gate valves to isolate them during ALD precursor exposures.

for ALD growth of lanthanum oxide, one of the potential candidates for a high-permittivity $(\kappa=\sim 20-27)$ gate dielectric for future complementary metal oxide semiconductor (CMOS) devices. ${ }^{17-20}$ The synthesis and properties of $\mathrm{La}\left({ }^{i} \mathrm{Pr}-\mathrm{MeAMD}\right)_{3}$ have been described by Gordon et al. ${ }^{6}$ This precursor molecule has higher volatility $\left(80^{\circ} \mathrm{C} / 0.04 \text { Torr }\right)^{6}$ than previously known lanthanum sources and has been successfully demonstrated for the growth of both lanthanum oxide and lanthanum aluminate. ${ }^{21}$ A similar precursor, lanthanum tris $\left(N, N^{\prime}\right.$-diisopropylformamidinate) is slightly more volatile and is expected to have surface chemistry similar to that of the precursor that we studied. ${ }^{22}$

\section{Experimental Section}

For this study, double-sided polished, float-zone-grown (lightly B-doped, $\rho \sim 10 \Omega \mathrm{cm}$ ) $\mathrm{Si}(111)$ wafers are used. Atomically flat hydrogen-terminated $\mathrm{Si}(111)$ surfaces are prepared by immersion for $1 \mathrm{~min}$ in $\mathrm{HF}(\sim 20 \%)$ and for $2 \mathrm{~min}$ in $\mathrm{NH}_{4} \mathrm{~F}(\sim 49 \%)$ after $\mathrm{RCA}^{23}$ cleaning. The lanthanum precursor $\left(\mathrm{La}\left({ }^{i} \mathrm{Pr}-\mathrm{MeAMD}\right)_{3}\right)$ is kept at $\sim 130{ }^{\circ} \mathrm{C}$, and the Si sample temperature is varied between 200 and $300{ }^{\circ} \mathrm{C}$. Heavy water $\left(\mathrm{D}_{2} \mathrm{O}\right)$ is used instead of $\mathrm{H}_{2} \mathrm{O}$ to distinguish infrared vibrational bands related to growth chemistry from environmental water. $\mathrm{H}$-terminated Si samples are immediately loaded in a nitrogen (oxygen impurity $<10^{-5} \mathrm{ppm}$ )-purged reactor. Growth is performed in a home-built ALD reactor connected to a FTIR spectrometer (Thermo Nicolet 6700, frequency range of $400-4000 \mathrm{~cm}^{-1}$ ); its schematic is shown in Figure 1. A singletransmission geometry ( $74^{\circ}$ incidence) is used to optimize the study of modes in the $500-1500 \mathrm{~cm}^{-1}$ regions, minimize interferences and give good sensitivity to modes polarized perpendicular to the interface. ${ }^{24}$ The transmitted IR beam is focused onto a broadband mercury cadmium telluride (MCT/ $\mathrm{B})$ detector. The $\mathrm{KBr}$ windows for IR transmission are isolated during ALD precursor exposures by closing two gate valves located in front of the windows. Lanthanum tris $\left(N, N^{\prime}\right.$-diisopropylacetamidinate) carried by ultrapure $\mathrm{N}_{2}$ gas and water $\left(\mathrm{D}_{2} \mathrm{O}\right)$ are delivered alternatively to the ALD reactor through stainless steel tubing. After each precursor pulse, the reactor is purged and pumped for at least 5 min with ultrapure $\mathrm{N}_{2}$ gas to prevent cross gas phase reactions among precursors (i.e., CVD) and to eliminate byproducts after surface reactions. The reactor is also equipped with a differentially pumped quadrupole mass spectrometer (QMS, Stanford Research Systems) for gas phase analysis. Rutherford backscattering spectroscopy (RBS) characterization of lanthanum oxide films is performed ex situ with

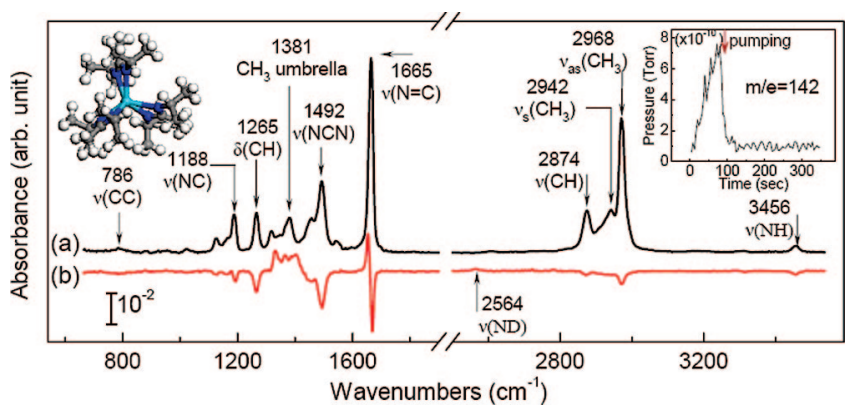

Figure 2. (a) FTIR absorption spectrum of gas phase $\mathrm{La}\left({ }^{i} \mathrm{Pr}-\mathrm{MeAMD}\right)_{3}$ (source temperature $125^{\circ} \mathrm{C}$ ) at 0.13 Torr, measured after it is introduced into the evacuated (0.08 Torr) reactor (used as reference). (b) Differential spectrum of the $\mathrm{La}\left({ }^{i} \mathrm{Pr}-\mathrm{MeAMD}\right)_{3}$ precursor after $\mathrm{D}_{2} \mathrm{O}$ is introduced, using the original $\mathrm{La}\left({ }^{i} \mathrm{Pr}-\mathrm{MeAMD}\right)_{3}$ spectrum (a) as reference. The inset in the left shows the ball-and-stick structure of the intact precursor, where the light blue, blue, gray, and white balls represent $\mathrm{La}, \mathrm{N}, \mathrm{C}$, and $\mathrm{H}$ atoms, respectively. The inset in the right shows QMS measurement during $\mathrm{La}\left({ }^{i} \mathrm{Pr}-\mathrm{MeAMD}\right)_{3}$ pulse monitoring $m / e=142$.

$2 \mathrm{MeV} \mathrm{He}{ }^{+}$ions. The detector is placed at a $160^{\circ}$ backscattering angle with respect to the surface normal to measure La density.

First-principles calculations based on density functional theory (DFT) are carried out to aid in the interpretation of infrared (IR) features of the intact La precursor with three amidinate ligands $\left(\mathrm{LaL}_{3}\right)$ and of an isolated amidine (a hydrogenated ligand, HL), where L represents a ligand. Gradient-corrected PBE functionals ${ }^{25}$ are used, as implemented in the DMol3 package. ${ }^{26}$ A numerical atomic basis set of double- $\zeta$ quality, augmented with additional polarization functions (DNP) with a real-space cutoff of $5.8 \AA$ is employed in this work. For La, the core electrons are represented with an effective relativistic semicore pseudopotential along with the DNP basis for valence electrons. ${ }^{27}$ The convergence criteria for structural optimizations are $1.0 \times 10^{-7}$ au and $1.0 \times 10^{-5} \mathrm{au} / \AA$ for energy and gradient, respectively.

\section{Results and Discussion}

Gas phase species in the ALD reactor are first investigated to determine the state of the precursor prior to reaching the sample. Figure 2a shows FTIR spectrum of the gas phase amidinate lanthanum precursor $\mathrm{La}\left({ }^{i} \mathrm{Pr}-\mathrm{MeAMD}\right)_{3}$ after it is introduced into the reactor ( 0.13 Torr). All the modes associated with an intact precursor are observed; notably, the terminal methyl groups $\left(\mathrm{CH}_{3}\right)$ at $2968 \mathrm{~cm}^{-1}$ (asymmetric stretching), $2942 \mathrm{~cm}^{-1}$ (symmetric stretching), $1381 \mathrm{~cm}^{-1}$ (umbrella deformation), and $\mathrm{CH}$ at $1317 \mathrm{~cm}^{-1}$ and $1265 \mathrm{~cm}^{-1}$ (bending) and weaker $\mathrm{C}-\mathrm{C}$ modes at $786 \mathrm{~cm}^{-1}$. When the precursor is intact with three chelating ligands, the $\pi$-electrons within the double bonds of the $\mathrm{N}-\mathrm{C}-\mathrm{N}$ linkage are delocalized, leading to a mode at $1492 \mathrm{~cm}^{-1}$. Although this delocalized $\mathrm{N}-\mathrm{C}-\mathrm{N}$ mode has been placed at $1665 \mathrm{~cm}^{-1}$ by Wilkins in $1974,{ }^{28}$ we show below that the strong mode at $1665 \mathrm{~cm}^{-1}$ and weaker mode at $3456 \mathrm{~cm}^{-1}$ are actually due to free amidine (HL) arising from the reaction of the precursor $\mathrm{LaL}_{3}$ with trace water.

Precursor dissociation in the presence of water would lead to the formation of a dissociated ligand with $\mathrm{H}$ attached (HL), producing two distinct species: (i) $\mathrm{HN}\left({ }^{i} \mathrm{Pr}\right)-\mathrm{C}(\mathrm{Me})=\mathrm{N}\left({ }^{i} \mathrm{Pr}\right)$ with distinct single and double bonds and (ii) $\mathrm{LaL}_{2} \mathrm{OH}$. To assist in assigning the observed bands and establish support for the appearance of the free ligand, DFT calculations at the PBE/ DNP level of theory are carried out to obtain vibrational frequencies, intensities, and normal modes for the parent 
TABLE 1: Calculated PBE/DNP Wavenumbers and General Mode Assignments Corresponding to the Key Observed Infrared Bands (indicated in Figure 2) Based on Calculations for the intact La Precursor $\left(\mathrm{LaL}_{3}\right)$, the $\mathrm{Hydrolysis} \mathrm{Product} \mathrm{LaL}_{2} \mathrm{OH}$, and Free Ligand HL

\begin{tabular}{|c|c|c|c|}
\hline observed IR $\left(\mathrm{cm}^{-1}\right)$ & $\operatorname{calcd}^{a}\left(\mathrm{~cm}^{-1}\right)$ & species & assignment \\
\hline $3456 / 2564$ & $3464 / 2534$ & HL/DL & $\mathrm{NH}(\mathrm{ND})$ stretching \\
\hline 2968 & $3110(3033)(3020)$ & $\mathrm{HL}\left(\mathrm{LaL}_{3}\right)\left[\mathrm{LaL}_{2} \mathrm{OH}\right]$ & $\mathrm{CH}_{3}$ asym stretching \\
\hline 2942 & $2950(2948)$ & $\mathrm{LaL}_{3}\left[\mathrm{LaL}_{2} \mathrm{OH}\right]$ & $\mathrm{CH}_{3}$ sym stretching \\
\hline $1665 / 1659$ & $1636 / 1625$ & HL/DL & $\mathrm{C}=\mathrm{N}$ stretching \\
\hline 1492 & $1517(1506)$ & $\mathrm{LaL}_{3}\left[\mathrm{LaL}_{2} \mathrm{OH}\right]$ & NCN stretching $+\mathrm{CH}_{3}$ scissor deformation \\
\hline 1450 & $1463(1456)$ & $\mathrm{LaL}_{3}\left[\mathrm{LaL}_{2} \mathrm{OH}\right]$ & $\mathrm{NCN}$ stretching $+\mathrm{CH}_{3}$ scissor deformation \\
\hline 1265 & $1304(1303)$ & $\mathrm{LaL}_{3}\left[\mathrm{LaL}_{2} \mathrm{OH}\right]$ & $\mathrm{CH}$ bending \\
\hline 1188 & 1185 (1193) (1193) & $\mathrm{HL}\left(\mathrm{LaL}_{3}\right)\left[\mathrm{LaL}_{2} \mathrm{OH}\right]$ & $\mathrm{CN}$ stretching $+\mathrm{CH}_{3}$ rocking \\
\hline 1126 & $1159(1158)$ & $\mathrm{LaL}_{3}\left[\mathrm{LaL}_{2} \mathrm{OH}\right]$ & $\mathrm{CH}_{3}$ rocking $+\mathrm{NCN}$ stretching \\
\hline 1022 & $1052(1052)$ & $\mathrm{LaL}_{3}\left[\mathrm{LaL}_{2} \mathrm{OH}\right]$ & $\mathrm{CH}_{3}$ rocking $+\mathrm{NCN}$ bending \\
\hline 786 & $774(774)$ & $\mathrm{LaL}_{3}\left[\mathrm{LaL}_{2} \mathrm{OH}\right]$ & $\mathrm{CC}$ stretching \\
\hline
\end{tabular}

${ }^{a}$ PBE/DNP calculated harmonic frequencies.
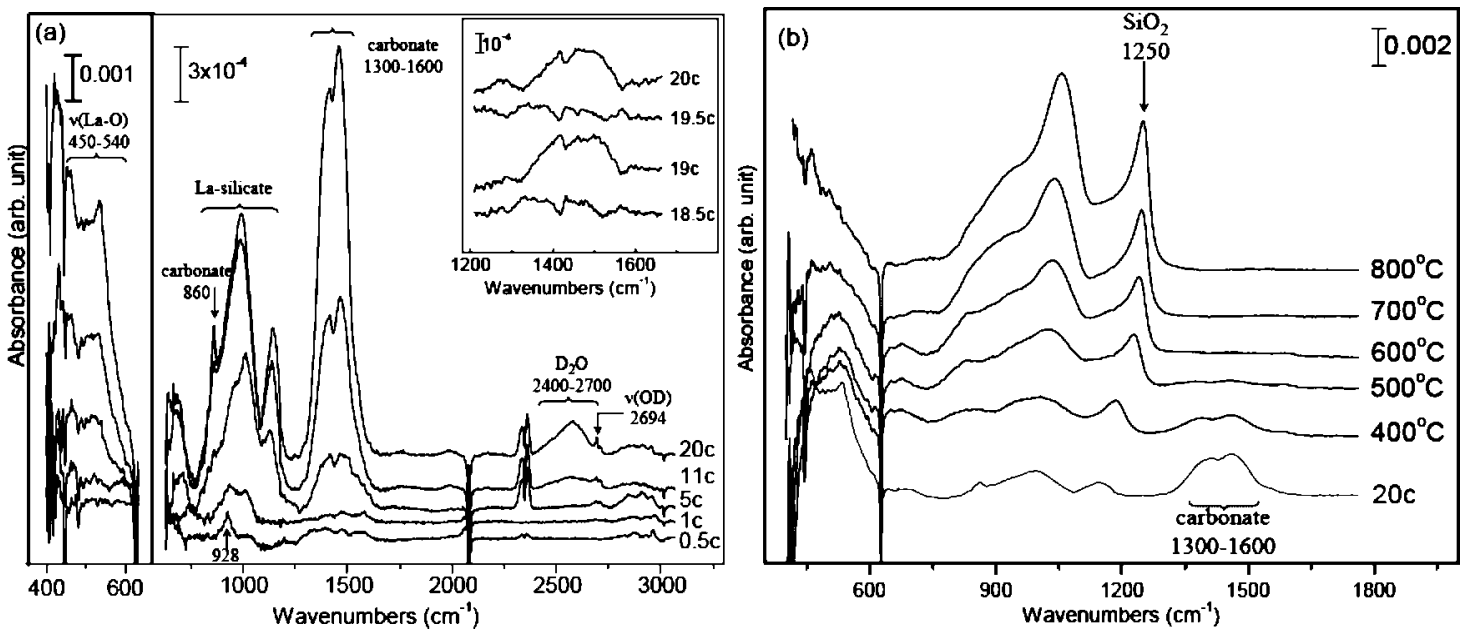

Figure 3. (a) FTIR absorption spectra of $\mathrm{H} / \mathrm{Si}(111)$ after subsequent exposures to La( $\left.{ }^{i} \mathrm{Pr}-\mathrm{MeAMD}\right)_{3}(0.5 \mathrm{c}), \mathrm{D}_{2} \mathrm{O}$ (1c) and 5th, 11th, and 20th ALD cycles with the Si sample at $200{ }^{\circ} \mathrm{C}$. The inset shows the differential spectra of half-cycles from the 18.5 th to 20 th cycles in the carbonate/acetate absorption range. (b) FTIR absorption spectra measured after postdeposition annealing from 400 to $800{ }^{\circ} \mathrm{C}$ with $100{ }^{\circ} \mathrm{C}$ increments in dry $\mathrm{N}_{2}(0.68$ Torr). All spectra are referenced to the initial H-terminated $\mathrm{Si}(111)$ surface.

precursor $\mathrm{LaL}_{3}$, the hydrolysis product $\mathrm{LaL}_{2} \mathrm{OH}$, and the free ligand HL, for comparison with experiment. Calculations for the free ligand show that the band at $1665 \mathrm{~cm}^{-1}$ (calcd 1636 $\mathrm{cm}^{-1}$ ) should be assigned to the localized $C=\mathrm{N}$ stretching of $\mathrm{HN}-\mathrm{C}=\mathrm{N}$ bonds in the hydrolyzed ligand (HL) rather than to the intact precursor $\mathrm{LaL}_{3}$. $\mathrm{La}\left({ }^{i} \mathrm{Pr}-\mathrm{MeAMD}\right)_{3}$ is known to be very reactive with water. Thus, HL may have been produced out of the reaction with trace water molecules in the reactor. Realtime mass spectroscopy (see the inset of Figure 2) in the ALD reactor confirms that a gas phase molecule with atomic mass 142 is produced, which corresponds to the HL species. Since $\mathrm{HL}$ is nonreactive, it remains in the gas phase and is preferentially detected by mass spectroscopy. It also does not affect film growth during the ALD process. In contrast, the $\mathrm{LaL}_{2} \mathrm{OH}$ product is not readily detected by mass spectrometry because it adsorbed/reacts on the reactor surfaces.

Figure 2b shows the spectral changes (differential spectra) occurring after exposing the lanthanum precursor to water $\left(\mathrm{D}_{2} \mathrm{O}\right)$. Most of the methyl-related bands of the $\mathrm{La}\left({ }^{i} \mathrm{Pr}-\mathrm{MeAMD}\right)_{3}$ precursor lose intensity, and some new bands are observed between 1300 and $1430 \mathrm{~cm}^{-1}$ after $\mathrm{D}_{2} \mathrm{O}$ exposure. The $\mathrm{N}-\mathrm{H}$ stretching at $3456 \mathrm{~cm}^{-1}$ is shifted to $2564 \mathrm{~cm}^{-1}$ due to isotope replacement $(\mathrm{N}-\mathrm{D})$, calculated in DFT at 3464 and $2534 \mathrm{~cm}^{-1}$. The isotope effect is also evident for the $C=\mathrm{N}$ stretching of
$\mathrm{N}-\mathrm{C}=\mathrm{N}$ in the HL (DL) free ligand that shifts from 1665 to $1659 \mathrm{~cm}^{-1}$. Calculations show a corresponding red shift of $\sim 11$ $\mathrm{cm}^{-1}$ with the H/D exchange. Table 1 presents a comparison of observed and computed IR wavenumbers and band assignments for the key modes discussed here and those of substantial intensity indicated in Figure 2.

The initial interaction of the precursor with the H-terminated Si(111) surface and subsequent ALD growth are investigated next. Figure 3a shows the FTIR absorption spectra of H/Si(111) exposed to the first $\mathrm{La}\left({ }^{i} \mathrm{Pr}-\mathrm{MeAMD}\right)_{3}(0.5 \mathrm{c}), \mathrm{D}_{2} \mathrm{O}(1 \mathrm{c})$ and $5 \mathrm{th}$, 11 th, and 20th cycles of ALD with the substrate at $200{ }^{\circ} \mathrm{C}$. The decrease in the $\mathrm{Si}-\mathrm{H}$ stretch intensity at $2083 \mathrm{~cm}^{-1}$ indicates that the $\mathrm{La}\left({ }^{i} \mathrm{Pr}-\mathrm{MeAMD}\right)_{3}$ precursor readily reacts with the atomically flat $\mathrm{H} / \mathrm{Si}(111)$ surface. The first $\mathrm{La}\left({ }^{i} \mathrm{Pr}-\mathrm{MeAMD}\right)_{3}$ pulse consumes about $40 \%$ of the surface hydrogen and more than $80 \%$ of the surface $\mathrm{H}$ by the end of the fifth cycle. Rutherford backscattering (RBS) measurements show $\sim 3 \times 10^{14}$ $\mathrm{cm}^{-2} \mathrm{La}$ atoms are on the surface after the first ALD cycle, corresponding to $\sim 40 \%$ of the $7.8 \times 10^{14} \mathrm{~cm}^{-2} \mathrm{H}$ density on $\mathrm{Si}(111)$. This indicates that for each reacted hydrogen, there is one $\mathrm{La}$ atom, confirming the following reaction: $\mathrm{LaL}_{3}+\mathrm{SiH}$ $\rightarrow \mathrm{Si}-\mathrm{LaL}_{2}+\mathrm{HL}(\mathrm{g})$. As we show below, the bonding to $\mathrm{Si}$ is actually mediated by an oxygen atom, forming $\mathrm{Si}-\mathrm{O}-\mathrm{LaL}_{2}$. 
The absorption spectrum measured after the first La precursor exposure $(0.5 \mathrm{c})$ in Figure $3 \mathrm{a}$ shows a feature at $928 \mathrm{~cm}^{-1}$ assigned to the $\mathrm{Si}-\mathrm{O}-\mathrm{La}$ stretching mode. ${ }^{29}$ Partial hydrolysis of the precursor into $\mathrm{LaL}_{2} \mathrm{OH}$ due to traces of water vapor in the reactor makes it possible to form $\mathrm{Si}-\mathrm{O}-\mathrm{LaL}_{2}$ directly. Although the formation of $\mathrm{Si}-\mathrm{LaL}_{2}$ is also possible, the $\mathrm{Si}-\mathrm{La}$ stretching band is below our accessible spectral range. Therefore, it is not possible to determine how much of the reaction with the surface is due to partially hydrolyzed precursor, although the intensity of the $928 \mathrm{~cm}^{-1}$ band points to almost a full monolayer coverage of $\mathrm{Si}-\mathrm{O}-\mathrm{La}$ bonds. The most intense vibrational mode at $1665 \mathrm{~cm}^{-1}$ of the gas phase La precursor does not appear on the surface absorption spectra, confirming that it belongs to the nonreactive gas product (HL) that is easily pumped out during the purge cycle of the ALD process. The broadband around $1300-1600 \mathrm{~cm}^{-1}$ originates from the surface amidinate ligand, and methyl groups are also observed in the $2800-3000 \mathrm{~cm}^{-1}$ spectral range.

With more ALD cycles, the $\mathrm{La}_{2} \mathrm{O}_{3}$ phonon modes start to develop in the $450-540 \mathrm{~cm}^{-1}$ range (left panel of Figure $3 \mathrm{a}$ ). There is evidence that these $\mathrm{ALD} \mathrm{La}_{2} \mathrm{O}_{3}$ films are polycrystalline, but it is not possible to determine the structure from the IR spectra. Several broad peaks between 800 and $1200 \mathrm{~cm}^{-1}$ are assigned to the $\mathrm{Si}-\mathrm{O}$ stretching of lanthanum silicate, $\mathrm{La}-\mathrm{O}-\mathrm{Si},{ }^{30}$ because they are located at frequencies lower than typical $\mathrm{Si}-\mathrm{O}$ vibrations due to a weakening of the $\mathrm{Si}-\mathrm{O}$ bond from electron density transfer from lanthanum to the $\mathrm{Si}-\mathrm{O}$. Spectra taken at near normal incidence (electric field parallel to the interface) indicate that the modes at 985 and $1170 \mathrm{~cm}^{-1}$ are polarized perpendicular to the surface; that is, they have characteristics of the longitudinal optical phonons. Altogether, these observations are consistent with the formation of a very thin lanthanum silicate layer in the vicinity of the interface, in addition to the $\mathrm{Si}-\mathrm{O}-\mathrm{La}$ interfacial layer.

As the film gets thicker, carbonate and water $\left(\mathrm{D}_{2} \mathrm{O}\right)$ are detected in the films, as evidenced by the broad absorption in the $1300-1600$ and $2400-2700 \mathrm{~cm}^{-1}$ spectral regions, respectively. A doublet centered at $1460,1415 \mathrm{~cm}^{-1}$ and the band at $860 \mathrm{~cm}^{-1}$ suggest unidentately bound carbonate species. ${ }^{31} \mathrm{La}_{2} \mathrm{O}_{3}$ can react with ambient $\mathrm{CO}_{2}$, resulting in carbonate incorporation into the films. ${ }^{32-36}$ However, residual $\mathrm{CO}_{2}$ is negligible inside the reactor, and the film is not exposed to air during the whole ALD process. Therefore, any carbonate present in the film must have been generated by intrinsic surface reactions. It is likely that lanthanum carbonate is produced through thermal decomposition of lanthanum acetate. There is, in fact, evidence of some acetate species present on the surface, characterized by broad bands between about 600 and $700 \mathrm{~cm}^{-1}$ and between about 2800 and $3000 \mathrm{~cm}^{-1}$ (see Figure 3a). The areas under these bands (and the bands between 1300 and $1600 \mathrm{~cm}^{-1}$ ) grow almost linearly with the number of ALD cycles. The differential spectra measured after each half-cycle (inset of Figure 3a) show that the intensity of these vibrational modes increases after $D_{2} \mathrm{O}$ pulses rather than after $\mathrm{La}\left({ }^{i} \mathrm{Pr}-\mathrm{MeAMD}\right)_{3}$ pulses, which suggests that these bands arise from reactions between $\mathrm{D}_{2} \mathrm{O}$ and amidinate ligands remaining on the surface. Chemically plausible reactions of this type would include hydrolysis of amidinate ligands first to amides and amines by reaction 1 :

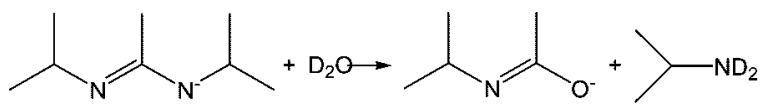

A second hydrolysis reaction 2 can then convert the amide to acetate and more isopropylamine, which is volatile and should be removed by the vacuum system.

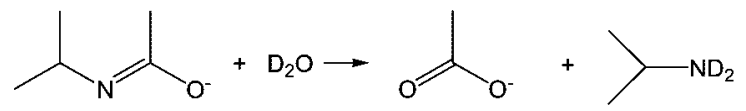

Some of the resulting acetate ions are likely to remain as impurities because the lanthanum-acetate bond is roughly as strong as a lanthanum-hydroxyl bond. Thus, there is little thermodynamic driving force to hydrolyzing the acetate ions to acetic acid, which would vaporize off the surface. The infrared spectrum of lanthanum acetate includes broad, intense bands at around 1450 and 1550 $\mathrm{cm}^{-1}$, as well as weaker bands between 600 and $700 \mathrm{~cm}^{-1}$ and between 2850 and $3000 \mathrm{~cm}^{-1}$. 37 A part of lanthanum acetate is then thermally decomposed on the surface, thus producing lanthanum carbonate that has a doublet centered at $1460,1415 \mathrm{~cm}^{-1}$ and the band at $860 \mathrm{~cm}^{-1}$. Thus, water and acetate ions together can explain all the observed impurity bands.

La atomic density is $5 \times 10^{15} / \mathrm{cm}^{2}$, according to ex situ RBS measurements of 20-cycle lanthanum oxide films deposited at $200{ }^{\circ} \mathrm{C}$. Assuming a density of bulk $\mathrm{La}_{2} \mathrm{O}_{3}$ of $6.51 \mathrm{~g} / \mathrm{cm}^{3}$, the resulting lanthanum oxide film thickness is $21 \AA$. But due to the presence of lanthanum silicate at the interface and impurities in the film, the overall thickness of the film might be greater. Ex situ spectroscopic ellipsometry measurements on the same sample yield an overall thickness of $23 \AA$, in close agreement with our estimate.

Post deposition annealing at $500{ }^{\circ} \mathrm{C}$ almost completely removes all these broad bands (see Figure $3 b$ ) and $\mathrm{D}_{2} \mathrm{O}$ (not shown) arising from impurities in the film. Since all these impurities contain oxygen, their thermal decomposition/reaction can provide the excess oxygen necessary to grow the interfacial silicon oxide layer observed upon annealing (see Figure 3b), in agreement with previous observations. ${ }^{38}$

The results in Figure $3 \mathrm{~b}$ suggest that the incorporation of impurities can be substantially decreased by heating the substrate at moderate temperatures $\left(\leq 400{ }^{\circ} \mathrm{C}\right)$ without substantially increasing the interfacial $\mathrm{SiO}_{2}$ layer. Indeed, the intensities in the regions $1300-1600$ and $2800-3000 \mathrm{~cm}^{-1}$ for acetate/ carbonate and $2400-2700 \mathrm{~cm}^{-1}$ for $\mathrm{D}_{2} \mathrm{O}$ are weakened substantially for ALD growth at $300{ }^{\circ} \mathrm{C}$ (Figure 4). The inset of Figure 4 shows the differential spectra around the $\mathrm{Si}-\mathrm{H}$ stretching mode, each of which is referenced to the previous spectrum. $\mathrm{La}\left({ }^{i} \mathrm{Pr}-\mathrm{MeAMD}\right)_{3}$ reacts with surface hydrogen very strongly at $300{ }^{\circ} \mathrm{C}$, consuming almost all $\mathrm{Si}-\mathrm{H}$ bonds in five ALD cycles. Although the amount of interfacial $\mathrm{SiO}_{2}$ is increased as compared to the same treatment with $\mathrm{Si}$ at $200{ }^{\circ} \mathrm{C}$ ( $\sim 100 \%$ increase), the total average thickness of that interfacial layer is estimated to be only $\sim 5 \AA$, according to the integrated area under $\mathrm{SiO}_{2}$ modes, which has been normalized with respect to a chemical oxide grown by wet chemical oxidation of $\mathrm{H}$-terminated $\mathrm{Si}$ using the RCA method $(\sim 10 \AA)$. These observations suggest that $300{ }^{\circ} \mathrm{C}$ is a good substrate temperature for optimum growth.

There are, however, new features at 1990 and $2110 \mathrm{~cm}^{-1}$ observed after each La precursor pulse when Si is held at 300 ${ }^{\circ} \mathrm{C}$. Their intensities are dramatically reduced after each subsequent $\mathrm{D}_{2} \mathrm{O}$ pulse. The frequencies of these two bands are very close to those of $\mathrm{Si}-\mathrm{H}$ stretching modes on modified $\mathrm{Si}$ surfaces, but their integrated areas are much greater than that of the initial $\mathrm{Si}-\mathrm{H}$ stretching mode. Their origin is likely involving $\mathrm{CN}$, since there is evidence in the literature that the 


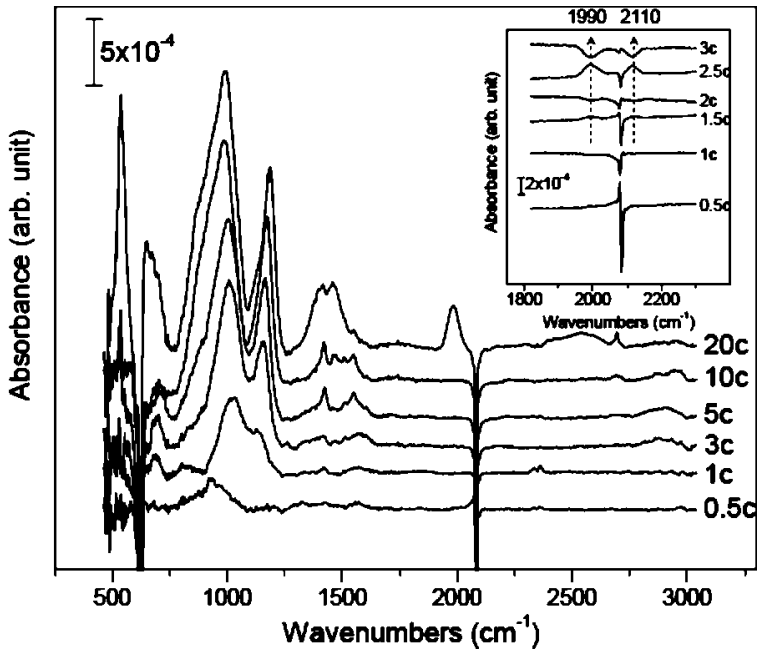

Figure 4. Absorption spectra of $\mathrm{H} / \mathrm{Si}(111)$ after it is exposed to the first $\mathrm{La}\left({ }^{i} \mathrm{Pr}-\mathrm{MeAMD}\right)_{3}(0.5 \mathrm{c}), \mathrm{D}_{2} \mathrm{O}(1 \mathrm{c})$ and 5 th, 10th and 20th cycles of ALD at $300{ }^{\circ} \mathrm{C}$. The inset is the differential spectra of half-cycles from 0.5 th to third cycle in the $1900-2200 \mathrm{~cm}^{-1}$ range.

stretching vibration of the triple bond $(\mathrm{C} \equiv \mathrm{N})$ in the cyanamide $(\mathrm{N}-\mathrm{C} \equiv \mathrm{N})^{2-}$ or the double bond $(C=\mathrm{N})$ in the carbodiimide $(\mathrm{N}=\mathrm{C}=\mathrm{N})^{2-}$ occurs around $2000 \mathrm{~cm}^{-1}$, often in the form of two bands. ${ }^{39}$ The formation of the cyanamide (or carbodiimide) ions on the surface suggests ligand decomposition at $300{ }^{\circ} \mathrm{C}$ through $\beta$ - or $\delta$-hydrogen transfer within the ligand. Scheme 1 below shows possible decomposition pathways to cyanamide. Initially, $\beta$-hydrogen transfers can lead to the formation of $\mathrm{NH}$ bonds on the ligand, and propene $\left(\mathrm{C}_{3} \mathrm{H}_{6}\right)$ could be produced as a gas phase byproduct. $\mathrm{N} \equiv \mathrm{C}$ triple bonds could then be produced through the second $\beta$-hydrogen transfer with methane $\left(\mathrm{CH}_{4}\right)$ as a byproduct. This $\mathrm{N} \equiv \mathrm{C}$ triple bond can also be formed directly by $\delta$-hydrogen transfers from the intact ligand on the surface. Finally, cyanamide could be formed through additional $\beta$-hydrogen transfers with propene as a byproduct that is pumped off without further interaction with the surface.

Often, ligand decomposition on the surface leads to further growth within the half-cycle (self-reaction of the precursor), thereby destroying the self-limitation of the reaction. However, in this case, the decomposed ligands are not reactive with further precursor molecules and are removed from the surface by the subsequent water pulse, as evidenced by the loss of the intensity at 1990 and $2110 \mathrm{~cm}^{-1}$ (see the differential spectra in the inset of Figure 4). Thus, this ALD reaction remains self-limited, despite the ligand decomposition. In addition, the composition of the film remains the same, whether or not ligand decomposition takes place. In fact, the smaller decomposed ligand facilitates access of more precursor molecules to the surface (smaller steric interactions), speeding up the film growth. The fact that more ligand decomposition is seen at higher surface temperature indicates that there are energy barriers to these decomposition reactions.

Lanthanum oxide is known to be highly hygroscopic, forming lanthanum hydroxide when exposed to water vapor. Lanthanum hydroxide then slowly desorbs water again during lanthanum precursor cycles. CVD reactions can be dominant in these cases, and film thickness derived from ex situ Rutherford backscattering measurements confirms nonuniform film growth. Water adsorption/desorption problems due to the hygroscopic nature of $\mathrm{La}_{2} \mathrm{O}_{3}$ can be overcome by growing interpenetrating, waterimpervious layers, such as $\mathrm{Al}_{2} \mathrm{O}_{3}$ layers. For instance, Gordon et al. ${ }^{21}$ have successfully suppressed CVD reactions by depositing alternating layers of $\mathrm{La}_{2} \mathrm{O}_{3}$ and $\mathrm{Al}_{2} \mathrm{O}_{3}$.

To compare the effect of $\mathrm{Al}-\mathrm{O}$ components in the ALD-grown lanthanum oxide, a full cycle of trimethylaluminum (TMA) and $\mathrm{D}_{2} \mathrm{O}$ is introduced after each $\mathrm{La}\left({ }^{i} \mathrm{Pr}-\mathrm{MeAMD}\right)_{3} / \mathrm{D}_{2} \mathrm{O}$ cycle. Figure 5a shows differential spectra of $\mathrm{H} / \mathrm{Si}(111)$ exposed to alternating ALD cycles at $300{ }^{\circ} \mathrm{C}$. Interfacial $\mathrm{SiO}_{2}$ is formed after the first complete $\mathrm{La} / \mathrm{D}_{2} \mathrm{O}$ cycle at this temperature in addition to lanthanum silicate, as evidenced by the modes centered around 1034 and 1155

\section{SCHEME 1: Possible Decomposition Pathways from Amidinate Ligand to Cyanamide ${ }^{a}$}

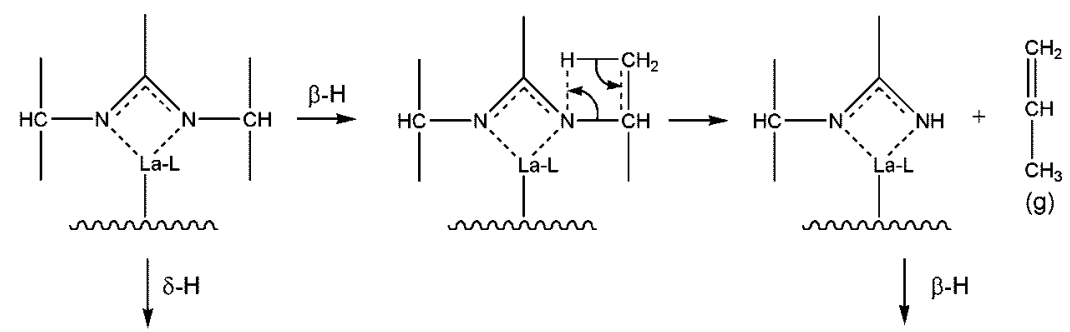

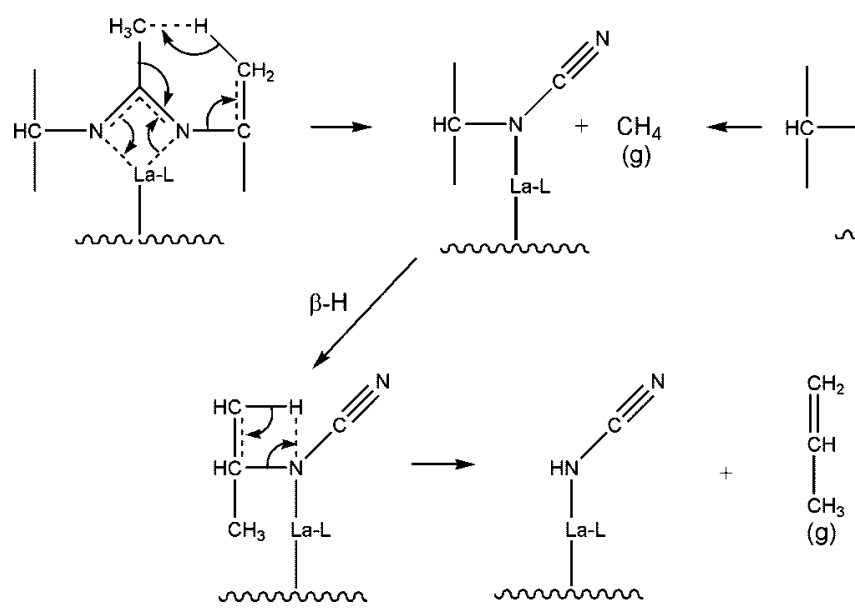

${ }^{a} \mathrm{~L}$ represents an additional undecomposed amidinate ligand attached to the same La atom. 

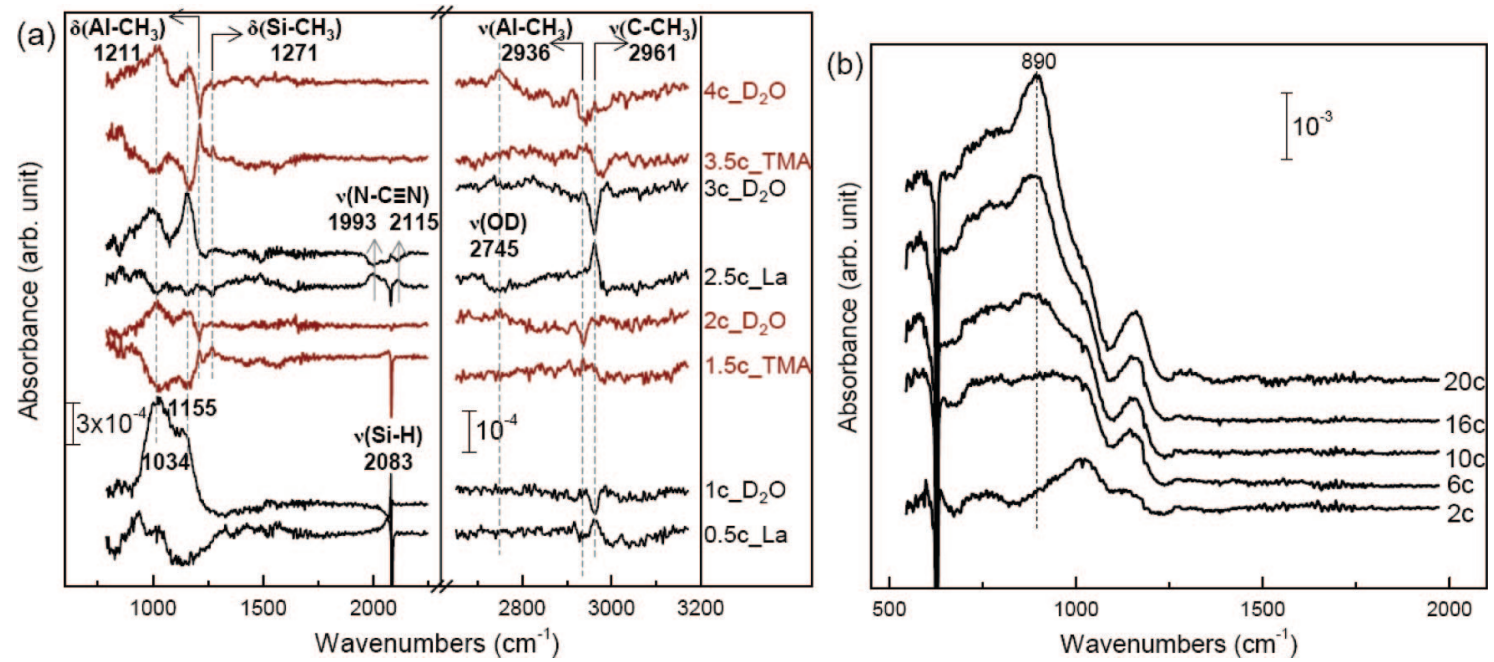

Figure 5. (a) Differential spectra of $\mathrm{H} / \mathrm{Si}(111)$ upon exposure at $300{ }^{\circ} \mathrm{C}$ to $\mathrm{La}\left({ }^{i} \operatorname{Pr}-\mathrm{MeAMD}\right)_{3}\left(0.5 \mathrm{c} \_\mathrm{La}\right), \mathrm{D}_{2} \mathrm{O}\left(1 \mathrm{c} \_\mathrm{D}_{2} \mathrm{O}\right)$ and trimethylaluminum (1.5c_TMA), $\mathrm{D}_{2} \mathrm{O}\left(2 \mathrm{c} \_\mathrm{D}_{2} \mathrm{O}\right)$ up to the fourth ALD cycle. Each spectrum is referenced back to the previously treated surface. (b) Absorbance spectra after $2,6,10,16$, or 20 cycles, referenced to the initial $\mathrm{H} / \mathrm{Si}(111)$.

$\mathrm{cm}^{-1}$ ("1c_ $\mathrm{D}_{2} \mathrm{O}$ " in Figure 5a). The slight loss of these modes after the first TMA pulse ("1.5c_TMA" in Figure 5a) shows the disruption of the oxide matrix due to TMA. The vibrational mode at $1211 \mathrm{~cm}^{-1}$ is assigned to $\mathrm{CH}$ bending of $\mathrm{Al}$-bonded methyl groups. It is lower than that of $(\mathrm{Si}-\mathrm{O}-\mathrm{Al})-\mathrm{CH}_{3}$ by $\sim 6 \mathrm{~cm}^{-1}$, probably because it is in $\mathrm{La}-\mathrm{O}-\mathrm{Al}-\mathrm{CH}_{3}$ arrangements. This band at $1211 \mathrm{~cm}^{-1}$ displays a ligand exchange behavior with the OD band at $2745 \mathrm{~cm}^{-1}$ upon $\mathrm{D}_{2} \mathrm{O}$ exposure, confirming the expected reaction with $\mathrm{Al}-\mathrm{CH}_{3}$.

The mode at $1271 \mathrm{~cm}^{-1}$ has been assigned to the umbrella mode of methyl groups bonded directly to $\mathrm{Si}$ atoms ${ }^{40}$ suggesting that there might be some methyl transfer from TMA to the remaining surface $\mathrm{H}-\mathrm{Si}$ bonds. Interestingly, the second $\mathrm{La}\left({ }^{i} \mathrm{Pr}-\right.$ MeAMD) $)_{3}$ pulse appears to reacts with $\mathrm{Si}-\mathrm{CH}_{3}$, as evidenced by the negative peak at $1271 \mathrm{~cm}^{-1}$ (see "2.5c_La"), and the same phenomenon is observed after the third La-precursor dosing (not shown). Surface $\mathrm{H}$ atoms are all consumed by then, and the mode at $1271 \mathrm{~cm}^{-1}$ does not occur any more after the third $\mathrm{La} / \mathrm{D}_{2} \mathrm{O}$ cycle. It is not certain why the strong $\mathrm{Si}-\mathrm{CH}_{3}$ bond reacts with $\mathrm{La}\left({ }^{i} \mathrm{Pr}-\mathrm{MeAMD}\right)_{3}$. On the other hand, TMA pulses after complete $\mathrm{La} / \mathrm{D}_{2} \mathrm{O}$ cycles appear to react with residual surface amidinate ligands, as evidenced by the loss of the modes around 1300-1600 $\mathrm{cm}^{-1}$ ("1.5_TMA" and "3.5c_TMA"). Overall, these interactions between the two metal precursors result in the substantial decrease of $\mathrm{C}$ impurity incorporation into the lanthanum aluminate films.

The cyanamide (or carbodiimide) species observed at 1993 and $2115 \mathrm{~cm}^{-1}$ due to decomposition of the La precursor react with the subsequent water pulse as illustrated above ("2.5c_La" and " $3 c_{-} \mathrm{D}_{2} \mathrm{O}$ "). The right panel of Figure 5a shows the frequency of the methyl stretching mode depends on the metal precursor it is attached to. For Al, it is at $2936 \mathrm{~cm}^{-1}$, and for $\mathrm{La}$, it is at $2961 \mathrm{~cm}^{-1}$.

Figure $5 \mathrm{~b}$ shows the absorbance spectra of the same surface after 20 such alternate ALD cycles referenced to the initial $\mathrm{H} / \mathrm{Si}(111)$ surface. Compared to the 10-cycle spectrum for pure lanthanum oxide in Figure 5 ("10c"), the vibrational signature of impurities in the $1300-1600 \mathrm{~cm}^{-1}$ region is almost completely absent. This suppression of impurity incorporation is mainly due to the interaction of TMA with the surface amidinate ligand, as described above. However, the interfacial $\mathrm{SiO}_{2}$ growth is comparable because the TMA/ $\mathrm{D}_{2} \mathrm{O}$ ALD cycle itself produces interfacial oxide at this temperature. ${ }^{41} \mathrm{~A}$ strong peak centered at $890 \mathrm{~cm}^{-1}$ appears and can be attributed to $\mathrm{La}-\mathrm{O}-\mathrm{Al}$ phonon absorption. The La atom surface density measured by Rutherford backscattering $\left(3.5 \times 10^{15} \mathrm{~cm}^{2}\right.$ after 20 cycles at $\left.300{ }^{\circ} \mathrm{C}\right)$ confirms that the lanthanum aluminate film thickness is uniform over the whole sample area, suggesting that CVD reactions are minimized.

\section{Summary and Conclusions}

The IR spectroscopic investigation of the growth of $\mathrm{La}_{2} \mathrm{O}_{3}$ on $\mathrm{H}$-terminated $\mathrm{Si}$ surfaces using an amidinate precursor has shown that, due to precursor reaction with residual water vapor, the initial interaction of $\mathrm{La}\left({ }^{i} \mathrm{Pr}-\mathrm{MeAMD}\right)_{3}$ with $\mathrm{H} / \mathrm{Si}$ involves the formation of a $\mathrm{Si}-\mathrm{O}-\mathrm{La}$ bond at the interface. Despite the large size of the precursor (i.e., potential steric interactions), there is complete reaction of all surface $\mathrm{Si}-\mathrm{H}$ bonds within a few ALD cycles $\left(\sim 10\right.$ cycles at $200{ }^{\circ} \mathrm{C}$ and 5 cycles at 300 ${ }^{\circ} \mathrm{C}$ ). This reaction is facilitated at $300{ }^{\circ} \mathrm{C}$ by the fact that the adsorbed precursor readily dissociates to form much smaller cyanamide (or carbodiimide) species that readily react with water pulses. The size and partial reactivity of the precursor contribute to the observation of trapped acetate and carbonate impurities, produced upon water interaction with adsorbed ligands during growth. The concentration of these impurities decreases at higher growth temperatures or upon post annealing, possibly leading to carbon contamination of the films. In general, the growth of pure $\mathrm{La}_{2} \mathrm{O}_{3}$ films is difficult because they are highly hygroscopic, leading to thickness nonuniformities on a macroscopic scale. Introducing alternating TMA $+\mathrm{D}_{2} \mathrm{O}$ ALD cycles suppresses CVD-like reactions and minimizes the acetate/ carbonate incorporation.

Acknowledgment. This work was supported by the National Science Foundation (CHE-0415652 and CHE-0354213). The lanthanum precursor was supplied by the Advanced Thin-Film Technologies Group at Rohm and Haas Electronic Materials. We appreciate assistance from Dr. Leonard N. J. Rodriguez and Dr. Harish Bhandari in handling the precursor, and Dr. Leszek Wielunski in taking RBS measurements.

\section{References and Notes}

(1) Ritala, M.; Leskelä, M. In Handbook of Thin Film Materials; Nalwa, H. S., Ed.; Academic Press, San Diego, 2001; Vol. 1.

(2) Luo, Y.; Yao, Y.; Shen, Q.; Sun, J.; Weng, L. J. Organomet. Chem. 2002, 662, 144. 
(3) Vendemiati, B.; Prini, G.; Meetsma, A.; Hessen, B.; Teuben, J. H.; Traverso, O. Eur. J. Inorg. Chem. 2001, 2001, 707. 128.

(4) Boere, R. T.; Cole, M. L.; Junk, P. C. New J. Chem. 2005, 29,

(5) Kissounko, D. A.; Zabalov, M. V.; Brusova, G. P.; Lemenovskii, D. A. Russ. Chem. Rev. 2006, 75, 351.

(6) Lim, B. S.; Rahtu, A.; Park, J. S.; Gordon, R. G. Inorg. Chem. $\mathbf{2 0 0 3}, 42,7951$

(7) Lim, B. S.; Rahtu, A.; Gordon, R. G. Nat. Mater. 2003, $2,749$.

(8) Dagorne, S.; Guzei, I. A.; Coles, M. P.; Jordan, R. F. J. Am. Chem. Soc. 2000, 122, 274

(9) Barker, J.; Kilner, M. Coord. Chem. Rev. 1994, 133, 219.

(10) Edelmann, F. T. Chem. Rev. 1994, 137, 403.

(11) Kim, K. H.; Farmer, D. B.; Lehn, J.-S. M.; Rao, P. V.; Gordon, R. G. Appl. Phys. Lett. 2006, 89, 133512.

(12) Li, Z.; Rahtu, A.; Gordon, R. G. J. Electrochem. Soc. 2006, 153 C787.

(13) de Rouffignac, P.; Park, J.-S.; Gordon, R. G. Chem. Mater. 2005 , 17, 4808

(14) de Rouffignac, P.; Yousef, A. P.; Kim, K. H.; Gordon, R. G. Electrochem. Solid-State Lett. 2006, 9, F45.

(15) de Rouffignac, P.; Gordon, R. G. Chem. Vapor Dep. 2006, 12, 152

(16) Li, H.; Farmer, D. B.; Gordon, R. G.; Lin, Y.; Vlassak, J. J. Electrochem. Soc. 2007, 154, D642.

(17) Devine, R. A. B. J. Appl. Phys. 2003, 93, 9938

(18) Yamada, H.; Shmizu, T.; Kurokawa, A.; Ishii, K.; Suzuki, E. J. Electrochem. Soc. 2003, 150, G429.

(19) Jin, H. J.; Choi, D. J.; Kim, K. H.; Oh, K. Y.; Hwang, C. J. Jpn. J. Appl. Phys., Part 1 2003, 42, 3519.

(20) Wu, Y. H.; Yang, M. Y.; Chin, A.; Chen, W. J.; Kwei, C. M. IEEE Electron Device Lett. 2000, 21, 341.

(21) Lim, B. S.; Rahtu, A.; Rouffignac, P. D.; Gordon, R. G. Appl. Phys. Lett. 2004, 84, 3957.

(22) Gordon, R. G.; Lehn, J.-S.; Liu, Y.; Kim, K. H.; Li, Z.; Coulter, M.; Li, H.; Pugh, R.; Shenai, D. AVS 75th International Conference on Atomic Layer Deposition, San Jose, CA, 2007 (published on CD-ROM by AVS)
(23) Reinhardt, K. A.; Kern, W. Handbook of Silicon Wafer Cleaning Technology, 2nd ed.; Andrew, W., Ed.; Norwich: New York, 2007.

(24) Chabal, Y. J. Surf. Sci. Rep. 1988, 8, 211.

(25) Perdew, J. P.; Burke, K.; Ernzerhof, M. Phys. Rev. Lett. 1996, 77, 3865

(26) Delley, B. J. Chem. Phys. 2000, 113 (18), 7756.

(27) Delley, B. Phys. Rev. B 2002, 66, 155125.

(28) Wilkins, J. D. J. Organomet. Chem. 1974, 80, 349

(29) Ono, H.; Katsumata, T. Appl. Phys. Lett. 2001, 78, 1832.

(30) Yamamoto, T.; Izumi, Y.; Hashimoto, H.; Oosawa, M.; Sugita, Y. Jap. J. Appl. Phys. 2006, 45, 6196.

(31) Klingenberg, B.; Vannice, M. A. Chem. Mater. 1996, 8, 2755.

(32) Suzuki, M.; Kagawa, M.; Syono, Y.; Hirai, T. J. Cryst. Growth $1991,112,621$.

(33) De Asah, A. M.; Critchley, J. T. S.; Nix, R. M. Surf. Sci. 1998, 405, 201.

(34) Gougousi, T.; Niu, D.; Ashcraft, R. W.; Parsons, G. N. Appl. Phys. Lett. 2003, 83, 3543

(35) Nieminen, M.; Putkonen, M.; Niinisto, L. Appl. Surf. Sci. 2001, 174,155 .

(36) Cheng, J. B.; Li, A. D.; Shao, Q. Y.; Ling, H. Q.; Wu, D.; Yang, Y.; Bao, Y. J.; Wang, M.; Liu, Z. G.; Ming, N. B. Appl. Surf. Sci. 2004, 233,91 .

(37) da Rocha, S. M. R.; da Silva, C. A.; Abrao, A. J. Alloys Compd. 2002, 344, 389.

(38) Leskelä, M.; Ninistö, L. In Handbook on the Physics and Chemistry of Rare Earths; Gschneider, K. A., Jr., Eyring, L., Eds.; Elsevier: Amsterdam, 1986; Vol. 8, chapter 56.

(39) Reckeweg, O.; Simon, A. Z. Naturforsch. 2003, 58b, 1097.

(40) Kwon, J.; Dai, M.; Halls, M. D.; Chabal, Y. J. Chem. Mater. 2008, 20,3248 .

(41) Frank, M. M.; Chabal, Y. J.; Wilk, G. D. Apply. Phys. Lett. 2003, 82,4758

JP806027M 